MIDAS

Museus e estudos interdisciplinares

$1 \mid 2013$

Varia

\title{
Marcus Granato e Marta Lourenço - Coleções científicas luso-brasileiras: património a ser descoberto
}

Pedro Casaleiro

\section{(2) OpenEdition}

Journals

Edição electrónica

URL: http://journals.openedition.org/midas/194

DOI: 10.4000/midas. 194

ISSN: 2182-9543

Editora:

Alice Semedo, Paulo Simões Rodrigues, Pedro Casaleiro, Raquel Henriques da Silva, Ana Carvalho

Refêrencia eletrónica

Pedro Casaleiro, « Marcus Granato e Marta Lourenço - Coleções científicas luso-brasileiras: património a ser descoberto ", MIDAS [Online], 1 | 2013, posto online no dia 01 abril 2013, consultado no dia 22 setembro 2020. URL : http://journals.openedition.org/midas/194; DOI : https://doi.org/10.4000/ midas. 194

Este documento foi criado de forma automática no dia 22 setembro 2020.

\section{c) (i)(2)}

Midas is licensed under a Creative Commons Attribution-NonCommercial-ShareAlike 3.0 International License 


\title{
Marcus Granato e Marta Lourenço - Coleções científicas luso-brasileiras: património a ser descoberto
}

\author{
Pedro Casaleiro
}

\section{REFERÊNCIA}

Granato, Marcus e Marta Lourenço. 2010. Coleções científicas luso-brasileiras: património a ser descoberto. Rio de Janeiro: Museu de Astronomia e Ciências Afins. 382 páginas, ISBN: 978-85-60069-26-2.

1 Constitui uma obra invulgar, da iniciativa do Museu de Astronomia e Ciências Afins (MAST) do Rio de Janeiro, organizada por Marcus Granato e Marta Lourenço. O título é ambicioso pois o seu significado é mais abrangente do que o conteúdo. As imagens da capa assinalam o património científico de ciência e tecnologia, os instrumentos científicos em particular, deixando de fora o património de história natural e da saúde. Inclui apenas parte da história do património científico, numa perspetiva amplamente assumida pelos organizadores no artigo de contextualização da edição, apesar disso contém dois museus com acervo de história natural e dois museus de farmácia.

2 Trata-se do primeiro trabalho que aborda em conjunto as principais instituições portuguesas e brasileiras que detêm coleções de ciência e tecnologia, tendo como ponto de partida a cultura material técnico-científica destes países. Inclui ainda um anexo fotográfico a cores, que apresenta uma seleção de cerca de três centenas de objetos das coleções em estudo. As catorze instituições, oito brasileiras e seis portuguesas, são detentoras de uma parte muito significativa do património científico do Brasil e de Portugal. São museus jovens, criados nas últimas décadas do séc. XX ou na primeira do séc. XXI, com acervos de pequena a média dimensão. Os objetos são dos sécs. XIX e XX de produção europeia, a maioria dos países onde se desenvolveu a indústria de precisão (França, Inglaterra e Alemanha), os objetos de fabrico nacional, realizados pelos 
produtores locais, são a exceção. Esta rede de museus estabeleceu-se em 2006 para o desenvolvimento de uma ferramenta de normalização, um thesaurus de instrumentos científicos na língua portuguesa. Este documento é indispensável ao entendimento entre os diferentes interlocutores que partilham a mesma língua, no trabalho de catalogação das coleções de ciência e tecnologia, e pode ser adotado pelos restantes países de expressão portuguesa. As instituições que os tutelam são onze universidades ou institutos superiores, dois laboratórios de escolas do ensino secundário e um pelo Ministério da Ciência e Tecnologia do Brasil:

3 - Museu de Astronomia e Ciências Afins, MAST/MCT, Rio de Janeiro, criado em 1985, possui 2.000 objetos;

4 - Museu de Ciência e Técnica da Escola de Minas, Universidade Federal de Ouro Preto, MCTEM/UFOP, Minas Gerais, criado em 1995 a partir do antigo museu de mineralogia;

5 - Museu da Escola de Farmácia, Universidade Federal de Ouro Preto, MEF/UFOP, Minas Gerais, criado na década de 1960;

6 - Museu Dinâmico de Ciência e Tecnologia da Universidade Federal de Juiz de Fora, MDCT/UFJF, Minas Gerais, criado em 1999;

7 - Museu da Farmácia Lucas M. Amaral, Faculdade de Farmácia e Bioquímica da Universidade Federal de Juiz de Fora, MFLMA/UFJF, Minas Gerais, criado em 1972;

8 - Museu da Escola Politécnica, Rio de Janeiro, criado em 1970;

9 - Laboratório de Física do Colégio Pedro II, Rio de Janeiro, catalogação iniciada em 2007;

10 - Laboratório de Física da Escola Estadual Bento de Abreu de Araraquara, São Paulo, catalogação iniciada em 2007;

11 - Museu da Ciência da Universidade de Coimbra, Gabinetes de Física e História Natural criados em 1772, abertura do Museu da Ciência em 2006, 7.000 instrumentos;

12 - Museu de Ciência da Universidade do Porto, MCUP, criado em 1996, 2.000 a 3.000 objetos de física;

13 - Museu da Faculdade de Engenharia da Universidade do Porto, FEUPmuseu, criado em 2004, 1.300 objetos;

14 - Museu do Instituto Superior da Engenharia do Porto, MISEP, criado em 1999, 5.628 objetos, 4.000 estampas e desenhos, 372 fotografias;

15 - Museu de Ciência da Universidade de Lisboa, criado em 1985, integrado no Museu Nacional de História Natural e de Ciência, MNHNC, em 2012 (MNHN criado em 1858), 11.000 objetos, 30.000 volumes, 100.000 documentos;

16 - Museu de Física do Instituto Superior de Engenharia de Lisboa, MF/ISEL, criado depois de 1974, herdeiro de espólio de antigos museus industriais de Lisboa, desde 1852.

17 No conjunto, a publicação traça um quadro ainda incipiente da situação dos dois países no que respeita à gestão de coleções científicas. As práticas são centradas no levantamento e descrição dos acervos tendo em vista a organização e a conservação adequadas, assim como a informatização dos inventários. Destaca-se o papel das instituições promotoras do projeto, o MAST e o MNHNC, como força motriz que conduziu grande parte do desenvolvimento e aplicação das boas práticas museológicas. Grande parte dos artigos dá relevo à história institucional onde se encontram as coleções, em detrimento da história das coleções e dos objetos propriamente ditos. Aspeto que pode ser ultrapassado no futuro, através do desenvolvimento de abordagens 
transversais que integrem os contextos da criação, desenvolvimento, utilização dos instrumentos e o aprofundamento de questões sobre ciência e sociedade. São flagrantes os casos em que o espólio mais antigo se acabou por dividir entre várias instituições, como é o caso dos museus do Porto, o que implicará abordagens do conjunto. As diferentes narrativas contribuem para a construção de uma imagem, mais ou menos idêntica em ambos os países, que revela episódios de descontinuidade do papel da ciência na educação, muitas vezes dirigida às elites mas nem sempre, protagonizada por políticos ou docentes. A ciência passou por momentos altos, marcados pelos picos de aquisição de equipamentos para os laboratórios de ensino e investigação, e por momentos baixos, em que diferentes vicissitudes levaram ao desmembramento ou encerramento de instituições e à transferência, dispersão ou perda dos acervos.

Salienta-se a coleção mais antiga e significativa em Portugal, o gabinete de física do Museu da Ciência da Universidade de Coimbra, uma verdadeira joia do património científico europeu. No primeiro inventário, "Index Instrumentorum" de 1788, o seu autor, Dalla Bella, descreve-o como "...hum dos mais copiosos, e magníficos Gabinetes da Europa". Subsistem as duas salas originais e o teatro das lições, com um acervo exposto de cerca de 250 instrumentos do séc. XVIII aos quais se juntam mais 150 do séc. XIX. $O$ artigo desmistifica a ideia corrente de grande perda do acervo original que contava com mais de 580 objetos. Na verdade muitos eram acessórios ou complementos que se foram consumindo e os instrumentos desaparecidos terão possivelmente sucumbido, após cem anos de utilização.

Bertomeu et. al, dá-nos uma panorâmica sobre as coleções de instrumentos científicos em Espanha, completando a visão ibérica. Em muito semelhante à portuguesa, tem a agravante da perda da quase totalidade das coleções anteriores ao séc. XIX. Apenas sobreviveu a coleção de instrumentos dos "Reales Estudios de San Isidro de Madrid", que reunia cerca de duas centenas de peças no início do séc. XIX, hoje cedida ao "Museo Nacional de Ciencia y Tecnologia". Desenvolve o tema do estudo das coleções de física e química das escolas secundárias e de projetos de salvaguarda destas coleções em Espanha. Distingue a COMIC, "Comissió d'Instruments Científics", o grupo que preparou uma base de dados coletiva de três escolas permitindo uma análise comparativa do desenvolvimento das práticas pedagógicas e científicas. Fica em falta um artigo semelhante de Portugal, como o projeto coordenado por Isabel Malaquias concluído em 2008 sobre os "Instrumentos científicos antigos no ensino e divulgação da física" (http://baudafisica.web.ua.pt), ou o inventário online do Património Museológico da Educação, do Ministério da Educação em Portugal. Este apresenta 9.178 entradas de "física" e 2.448 de "química", que são objetos das coleções dos vários estabelecimentos de ensino, antigos liceus e escolas industriais (http://edumuseu.sg.min-edu.pt//).

Lourenço levanta problemáticas ou desafios centrais para os museus científicos em Portugal, extensíveis ao Brasil, entre os quais se salientam o desenvolvimento da documentação, a sustentabilidade e o reconhecimento, passando pela formação em museologia da ciência. Após a fase de organização, catalogação e conservação, tendo em conta as limitações de cada coleção, torna-se essencial promover o desenvolvimento da documentação como via para o suporte de estudos da cultura material e contribuição para a história da ciência. A maioria destes museus tem génese e gestão universitária, a sua sustentabilidade a longo prazo encontra-se ameaçada pelo rumo dos modelos de gestão das universidades, orientados para o ensino e captação de estudantes como garantia de financiamento. A falta de reconhecimento da cultura científica por parte 
dos Ministérios da Cultura, que se preocupam especialmente com os museus da sua tutela, são um verdadeiro entrave ao desenvolvimento dos museus de ciência. Outro dos desafios refere-se à formação e criação de massa crítica para o trabalho e investigação nesta área, uma vez que as instituições apresentam recursos humanos escassos e a maioria dos museus encontra-se na fase de catalogação das coleções, as alternativas colocam-se ao nível da criação de parcerias e de redes (regionais, nacionais e internacionais).

21 O último artigo introduz práticas de formação e investigação na área de estudos de objetos e gestão de coleções, confronta-nos com os resultados do impacto da formação universitária em museologia nas últimas duas décadas. Através da experiência do curso de Mestrado de Museologia da Universidade do Porto, um exemplo de sucesso refletido no crescimento de um tecido de profissionais dos museus, que contribuíram para o momento de viragem no início deste século através de uma nova atitude face aos públicos e reafirmação da identidade museal. Tal como indica Semedo: "O território que temos procurado construir é pois de profissão-em-ação, de espaço reflexivo e discussão crítica oferecendo uma museologia de possibilidades."

\section{AUTORES}

\section{PEDRO CASALEIRO}

Museu da Ciência, Universidade de Coimbra, Portugal, pcasaleiro@museudaciencia.org 